Supplemental Information for:

\title{
Insight into the role of water-soluble organic solvents for the Cloud Condensation Nuclei activation of cholesterol
}

Farima Barati , Qi Yao, and Akua A. Asa-Awuku “*

University of Maryland, Department of Chemical and Biomolecular Engineering

University of Maryland, Department of Chemistry and Biochemistry

*Correspondence: asaawuku@umd.edu; Tel.: +1-301-405-8527).

Abstract: The following document contains supplementary data, analysis and figures that pertain to the calibrations, statistical analysis and experimental set-up.

List of Figures and Tables

- Figure S1. Experimental setup using DMA or AAC as a classifier.

- Figure S2. $\left(\mathrm{NH}_{4}\right)_{2} \mathrm{SO}_{4}$ comparison of Electrical Mobility and AAC derived kappa values.

- Figure S3. Surface tension vs concentration of cholesterol in a) Ethanol; b) Isopropanol; c) Acetone mixed with three different volumes of water.

- Table S1. $\left(\mathrm{NH}_{4}\right)_{2} \mathrm{SO}_{4}$ Calibrated CCN Counter measurement data

- Table S2. ANOVA statistics for Electrical Mobility Kappa for 1 dryer data

- Table S3. ANOVA statistics for Electrical Mobility Kappa for 1 dryer and 2 dryers

- Table S4. ANOVA for AAC $x$ values for 1 dryer

- Table S5. ANOVA for AAC $\chi$ values for 1 dryer and 2 dryers.

- Table S6. ANOVA for Shape Factor $\chi$, at dae $=100 \mathrm{~nm}$

- Table S7. ANOVA statistics for Electrical Mobility Kappa with Shape Factor $\chi$ Correction

- Table S8. Alpha and Beta parameters used to plot Syskowski- Langmuir fit 


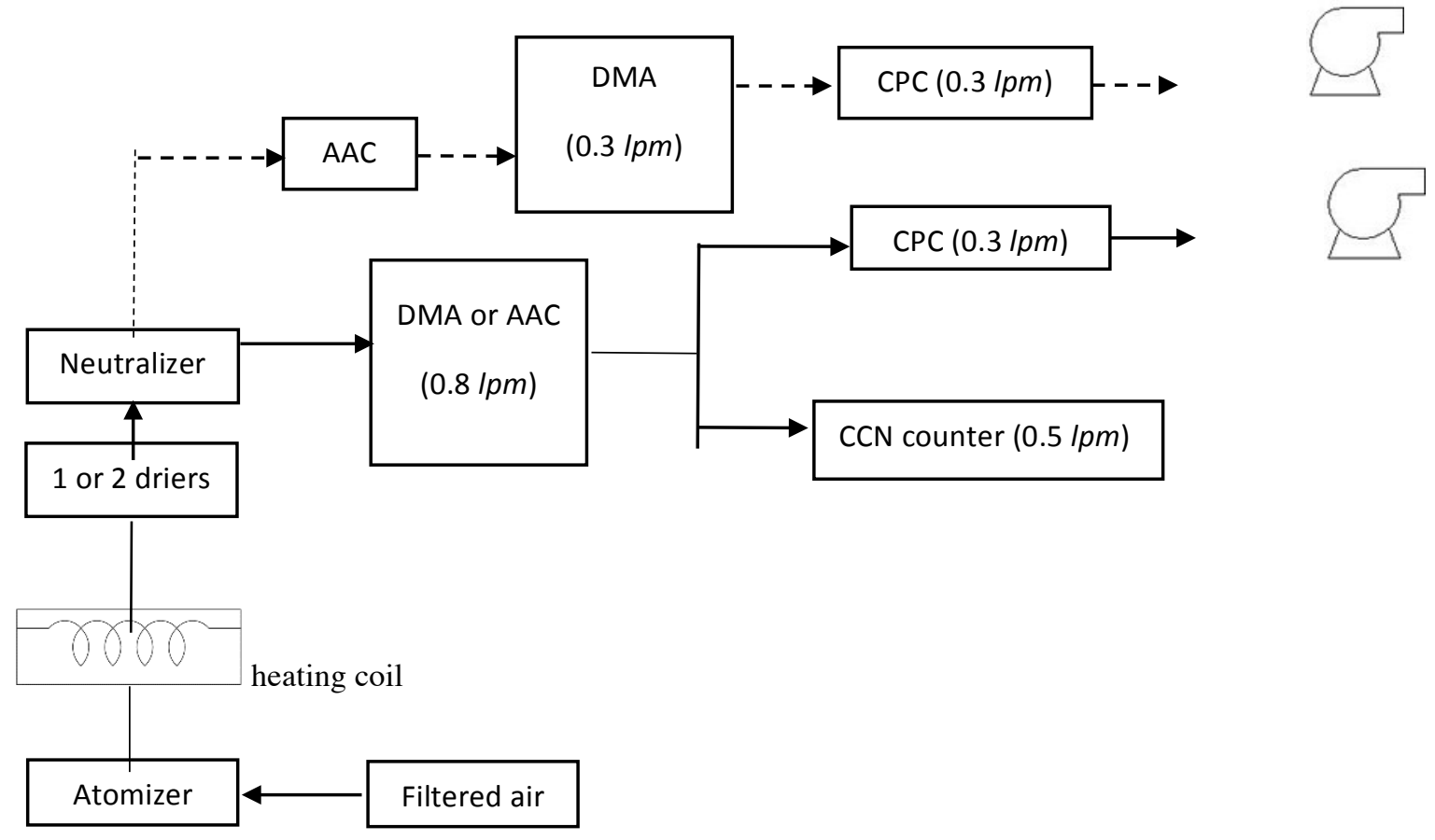

Figure S1. Experimental setup using DMA or AAC as a classifier. Sample flowrates are illustrated inside the parentheses. The setup shown with dashed line corresponds to the setup for shape factor.

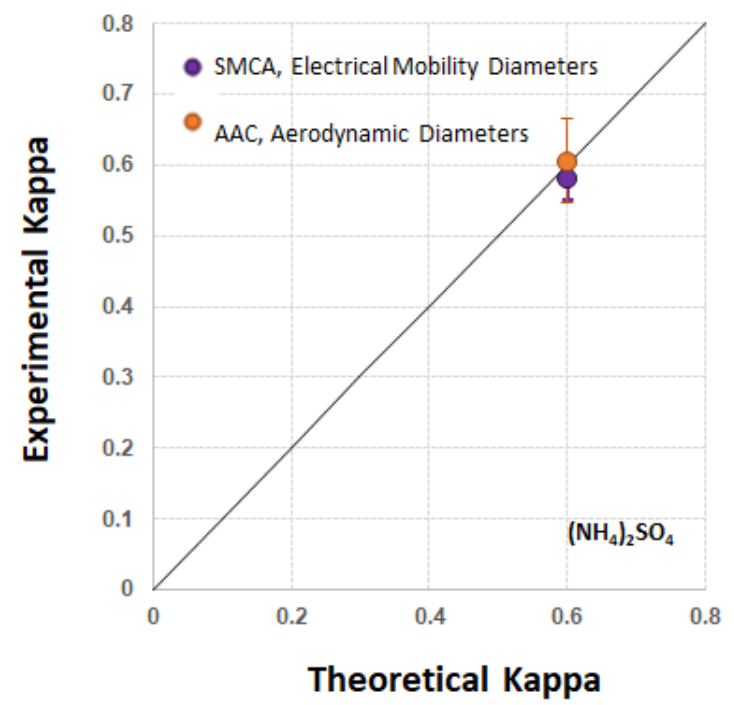

Figure S2. $\left(\mathrm{NH}_{4}\right)_{2} \mathrm{SO}_{4}$ comparison of Electrical Mobility and AAC derived kappa values. 

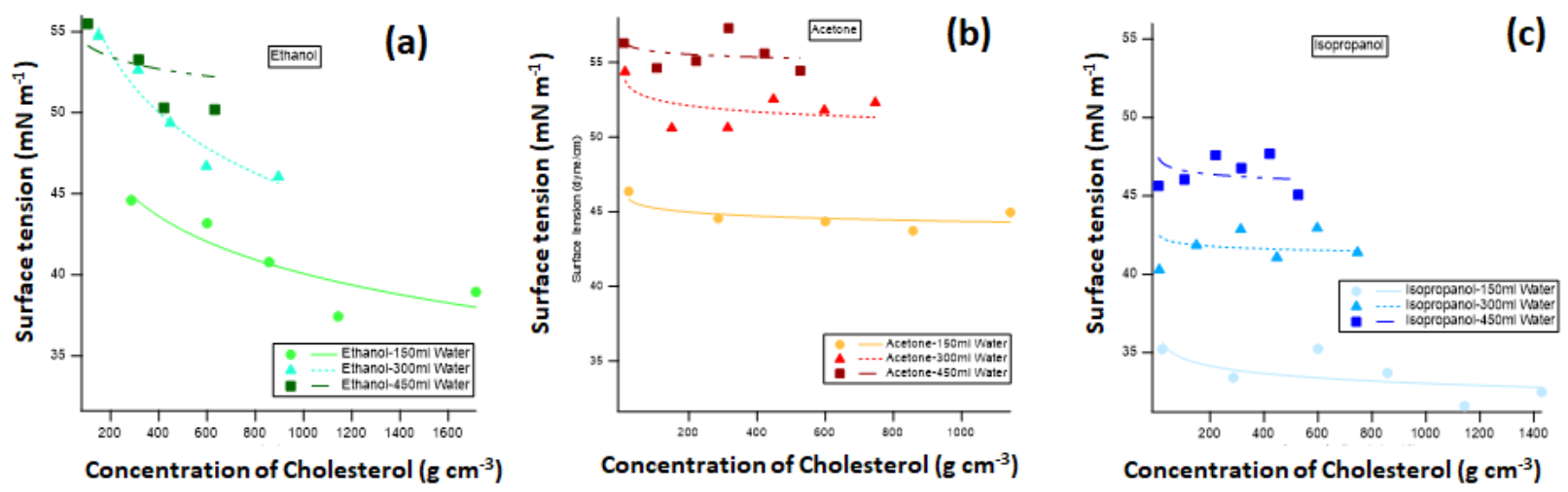

Figure S3. Surface tension vs concentration of cholesterol in a) Ethanol; b) Isopropanol; c) Acetone mixed with three different volumes of water.

\section{CCN Calibration with $\left(\mathrm{NH}_{4}\right)_{2} \mathrm{SO}_{4}$}

Table S1. (NH4)2SO4 Calibrated CCN Counter measurement data

\begin{tabular}{ccc}
\hline $\begin{array}{c}\text { Supersaturation } \\
\text { setting }(\%)\end{array}$ & $\begin{array}{c}\text { Calibrated } \\
\text { supersaturation }(\%)\end{array}$ & $\begin{array}{c}\text { Critical diameter, } D_{m o} \\
(\mathrm{~nm})\end{array}$ \\
\hline 0.2 & 0.18 & 86.42 \\
0.4 & $0.40 \pm 0.02$ & $52.42 \pm 1.56$ \\
0.6 & $0.56 \pm 0.04$ & $41.34 \pm 1.84$ \\
0.8 & $0.74 \pm 0.01$ & $34.96 \pm 0.39$ \\
1 & $0.95 \pm 0.01$ & $29.66 \pm 0.23$ \\
1.2 & $1.18 \pm 0.05$ & $25.72 \pm 0.73$ \\
1.4 & $1.31 \pm 0.02$ & $23.97 \pm 0.31$ \\
1.6 & $1.64 \pm 0.06$ & $20.71 \pm 0.54$ \\
1.8 & $1.87 \pm 0.02$ & $18.96 \pm 0.12$
\end{tabular}




\section{ANOVA (Analysis of variance)}

Factors considered in 2 Factorial Design for $\varkappa$ hygroscopicity values:

- Solvent used (Organic Solvent - Ethanol, Isopropanol, Acetone)

- Volume of Water added (Dilution, $150 \mathrm{ml}, 300 \mathrm{ml}$, and $450 \mathrm{ml}$ of added water)

- Number of Dryers ( 1 or 2 )

To determine which experimental design factor contributes the most variance to changes in the mean an analysis of variance (ANOVA) is performed. It is assumed that sample sizes greater than 40 follow the central limit theorem and normal probability distributions. Thus the mean of a treatment Error the factor will follow normal distributive properties and the probability that the mean of a treatment Error a given factor is different than a second mean can be quantified. The sources of variation describe the experimental design factors considered. SS is the sum of squares for a given factor. $D_{r}$ is the degrees of freedom. MS is the mean sum of squares approximated as the sum of squares divided by the degrees of freedom. MS for a factor is divided by the MS of the error to define F, the critical F-distribution statistic which is used to find the probability value (p-value) Type I significance. The significance value, $\alpha=5 \%$. $p$-values for both factors are less than 5\%; thus, we conclude that the null hypothesis $\left(H_{0}\right.$ : factor treatment effects $\left.=0\right)$ is rejected.

- Table S2. ANOVA statistics for Electrical Mobility Kappa for 1 dryer data

\begin{tabular}{lcrrrrr} 
ANOVA & \multicolumn{1}{c}{ MS } & \multicolumn{1}{c}{$F$} & \multicolumn{1}{c}{ P-value } & F crit \\
\hline $\begin{array}{l}\text { Source of } \\
\text { Variation }\end{array}$ & \multicolumn{1}{c}{ SS } & $d f$ & \multicolumn{1}{c}{ MS } & \\
\hline Sample & 0.005661 & 2 & 0.00283 & 4.56187 & 0.011388 & 3.034414 \\
Columns & 0.036963 & 2 & 0.018482 & 29.78683 & $2.99 \mathrm{E}-12$ & 3.034414 \\
Interaction & 0.007269 & 4 & 0.001817 & 2.928886 & 0.021665 & 2.410222 \\
Within & 0.145188 & 234 & 0.00062 & & & \\
& & & & & & \\
Total & 0.195081 & 242 & & & & \\
\hline
\end{tabular}

Table S3. ANOVA statistics for Electrical Mobility Kappa over 1 dryer and 2 dryers Analysis of Variance

\begin{tabular}{|c|c|c|c|c|c|}
\hline Source & DF & Adj SS & Adj MS & $\begin{array}{c}\text { F- } \\
\text { Value }\end{array}$ & P-Value \\
\hline Dryers & 1 & 0.01247 & 0.012474 & 26.30 & 0.000 \\
\hline Solvent & 2 & 0.01205 & 0.006027 & 12.71 & 0.000 \\
\hline Dilution & 2 & 0.03030 & 0.015152 & 31.95 & 0.000 \\
\hline Error & 390 & 0.18497 & 0.000474 & & \\
\hline Lack-of- & 12 & 0.02335 & 0.001946 & 4.55 & 0.00 \\
\hline Fit & & & & & \\
\hline $\begin{array}{l}\text { Pure } \\
\text { rror }\end{array}$ & 378 & 0.16162 & 0.000428 & & \\
\hline Total & 395 & 0.24477 & & & \\
\hline
\end{tabular}


Table S4. ANOVA for AAC $x$ values for 1 dryer

\begin{tabular}{lrrr} 
Analysis of Variance & \multicolumn{1}{c}{ F- } \\
Source & DF Adj SS Adj MS & Value P-Value \\
\hline Solvent & 20.0000010 .000000 & 1.79 & 0.279 \\
$\quad$ Dilution & 20.0000020 .000001 & 4.72 & 0.089 \\
Error & 40.0000010 .000000 & & \\
Total & 80.000004 &
\end{tabular}

Table S5. ANOVA for AAC $x$ values for 1 dryer and 2 dryers.

Analysis of Variance
\begin{tabular}{crrrr} 
Source & DF Adj SS Adj MS & Value P-Value \\
\hline Dryers & 10.0000210 .000021 & 24.27 & 0.000 \\
$\quad$ Solvent & 20.000006 & 0.000003 & 3.60 & 0.060 \\
$\quad$ Dilution & 20.0000010 .000000 & 0.55 & 0.592 \\
Error & 120.0000110 .000001 & & \\
Total & 170.000039 & & &
\end{tabular}

Table S6. ANOVA for Shape Factor $\chi$, at dae $=100 \mathrm{~nm}$ Analysis of Variance

\begin{tabular}{lrrrrr} 
& & & \multicolumn{2}{c}{ F- } \\
Source & DF & Adj & SS & Adj MS & Value P-Value \\
\hline Dryers & 1 & 0.024642 & 0.024642 & 7.97 & 0.015 \\
$\quad$ Solvent & 2 & 0.001312 & 0.000656 & 0.21 & 0.812 \\
$\quad$ Dilution & 2 & 0.009613 & 0.004807 & 1.55 & 0.251 \\
Error & 120.037115 & 0.003093 & & \\
Total & 170.072682 & & &
\end{tabular}

Table S7. ANOVA statistics for Electrical Mobility Kappa with Shape Factor $\chi$ Correction

\begin{tabular}{|c|c|c|c|c|c|}
\hline Source & $\mathrm{DF}$ & Adj ss & Adj MS & $\begin{array}{r}\text { F- } \\
\text { Value }\end{array}$ & P-Value \\
\hline Dryers & 1 & 0.11917 & 0.119172 & 42.04 & 0.000 \\
\hline Solvent & 2 & 0.05477 & 0.027386 & 9.66 & 0.000 \\
\hline Dilution & 2 & 0.24326 & 0.121631 & 42.91 & 0.000 \\
\hline Error & 390 & 1.10561 & 0.002835 & & \\
\hline $\begin{array}{l}\text { Lack-of- } \\
\text { Fit }\end{array}$ & 12 & 0.12624 & 0.010520 & 4.06 & 0.000 \\
\hline $\begin{array}{l}\quad \text { Pure } \\
\text { Error }\end{array}$ & 378 & 0.97937 & 0.002591 & & \\
\hline Total & 395 & 1.46992 & & & \\
\hline
\end{tabular}


Table S8. Alpha and Beta parameters used to plot Syskowski- Langmuir fit

\begin{tabular}{|c|c|c|}
\hline \multicolumn{2}{|c|}{ Parameter } \\
\hline Mixture & Alpha & Beta \\
\hline Ethanol- 150ml water & 0.0132 & 4.6600 \\
\hline Ethanol- 300ml water & 0.0180 & 0.1606 \\
\hline Ethanol- 450ml water & 0.0034 & $2.43 \times 10^{18}$ \\
\hline Isopropanol- 150ml water & 0.0027 & $1.99 \times 10^{47}$ \\
\hline Isopropanol- 300ml water & 0.0009 & $1.71 \times 10^{26}$ \\
\hline Isopropanol- 450ml water & 0.0013 & $1.9 \times 10^{27}$ \\
\hline Acetone- 150ml water & 0.0013 & $3.81 \times 10^{9}$ \\
\hline Acetone- 300ml water & 0.0025 & $3.92 \times 10^{21}$ \\
\hline Acetone- 450ml water & 0.0010 & \\
\hline
\end{tabular}

